The frequencies of four different $\beta$ thalassaemia alleles in a Brazilian population.

\begin{tabular}{lccr}
\hline Mutation & Type & $\begin{array}{c}\text { No of } \\
\text { chromosomes }\end{array}$ & $\%$ \\
\hline (1) CD 39 (C-T) & $\beta^{0}$ & 45 & $64 \cdot 3$ \\
(2) IVS-1 110 (G-A) & $\beta^{+}$ & 14 & $20 \cdot 0$ \\
(3) IVS-1 6 (T-C) & $\beta^{+}$ & 5 & $7 \cdot 1$ \\
(4) IVS-1 1 (G-A) & $\beta^{0}$ & 4 & $5 \cdot 7$ \\
(5) Unknown & & 2 & $2 \cdot 9$ \\
\hline
\end{tabular}

results, the four most common alleles account for $97.1 \%$ of the disease genes in Brazil. Two mutations, namely the nonsense mutation at codon $39(\mathrm{C} \rightarrow \mathrm{T})$ and the $\beta$ IVS-1-nt 110 $\mathrm{C} \rightarrow \mathrm{A}$ ), account for $84.3 \%$ of the thalassaemia alleles. Although approximately 31 thalassaemia mutations have been reported in (Mediterranean populations, ${ }^{2}$ the allele frequencies vary greatly from one country to another. Comparison of our data on the frequencies of $\beta$ thalassaemia alleles with other Mediterranean populations shows a close similarity between the allele distribution in south eastern Brazil and northern Italy, mainly the regions of Milan and Lombardia. ${ }^{6}$ This was to be expected based on the origin of Italian immigrants in Brazil. ${ }^{7}$ Most of them originated from northern Italy (Veneto, Piemonte, Lombardia, and Emiglia Romagna) and to a lesser extent from southern Italy (Campania and Calabria). ${ }^{6}$ Interestingly, the frequencies of different mutations reported among thalassaemia heterozygotes from central Portugal, ${ }^{8}$ where the $\beta$ IVS-1-nt 6 and $\beta$ IVS-1-nt 1 mutations reach high frequencies, are different from those observed in our study. In conclusion, the results presented here indicate that most of the thalassaemia genes in Brazil originated from Italian immigrants and a limited spectrum of mutation is found. They enable us to design a simple and accurate approach to prenatal diagnosis of $\beta$ thalassaemia in the country.

This study was supported in part by grants from FAPESP-Brazil.

C S B MARTINS A S RAMALHO
Department of Medical Genetics,
UNICAMP, São Paulo, Brazil. UNICAMP, São Paulo, Brazil.
M F SONATI Department of Clinical Pathology, UNICAMP, São Paulo, Brazil.

M S GONCALVES F F COSTA

Department of Clinical Medicine, Hemocentro da UNICAMP Caixa Posta 6198, Cep 13081, Campinas, SP, Brazil.

1 Kazazian $\mathrm{HH}$ Jr. The thalassemia syndromes: molecular basis and prenatal diagnosis in 1990. Semin Hematol 1990;27:209-28.

2 Zago MA, Costa FF. Hereditary haemoglobin disorders in Brazil. Trans $R$ Soc Trop Med disorders in Brazil.

3 Costa FF, Taella MA, Zago MA. Molecular bases of beta thalassemia in Brazil. Blood bases of beta
$1990 ; 76: 58 \mathrm{~A}$.

4 Costa FF, Tavella MH, Zago MA. Thalassemia intermedia and IVS-I-nt 6 homozygosis in Brazil. Braz f Med Biol Res 1991;24:157-61.

5 Amselem S, Nunes V, Vidaut M. Determination of the spectrum of $\beta$-thalassemia genes in Spain by use of dot-blot analysis of amplified $\beta$-globin DNA. Am f Hum Genet 1988;43:94 100.

6 Rosatelli MC, Tuveri T, Scalas MT, et al. Thalassemia mutations in the Italian population. Nouv Rev Fr Hematol 1991;33:441.

7 Saldanha PH. Efeito da migração sobre a estrutura genética de uma comunidade paulista. Boletim No 248 USP, 1968:226.

8 Ribeiro MLS, Baysal E, Kutlar F, et al. A novel $\beta^{\circ}$-thalassemia mutation in a population of central Portugal. Br $\mathcal{f}$ Haematol 1992;80:5678 .

\section{Autozygosity mapping, complex consanguinity, and autosomal recessive disorders}

Mapping of autosomal recessive disorders is more problematical than for autosomal dominant or X linked disorders.' Many autosomal recessive disorders are individually rare, making it difficult to collect sufficient numbers unless this is done on an international collaborative basis. In addition, in most parts of the world family sizes are limited, with it being uncommon for families to have more than three to four children and therefore making it unusual for there to be more than two affected sibs within a sibship.

Mathematical analysis of the power of nuclear families with autosomal recessive disorders has shown that in order to have high likelihood of showing linkage in gene mapping studies, inordinate numbers of families, preferably with multiple affected sibs, are required as described by Wong et al. ${ }^{2}$

Use of homozygosity mapping with affected offspring of first cousins has been advocated as far fewer families are needed to have the same likelihood of showing linkage, an approach originally suggested by Smith and more recently by Lander and Botstein. Morton ${ }^{5}$ has reminded us that this approach is more correctly called autozygosity mapping.

An estimate of the lod score under complete linkage to determine rapidly the potential usefulness of various consanguineous pedigrees for a single affected offspring can be derived by the use of the formula:

Elod $=\log _{10}\left[\frac{\mathrm{qrF}+(1-F) \mathrm{q}^{2} \mathrm{r}^{2}}{\left\{\mathrm{qF}+(1-\mathrm{F}) \mathrm{q}^{2}\right\}\left\{\mathrm{rF}+(1-\mathrm{F}) \mathrm{r}^{2}\right\}}\right]$.

The effect of variation in the disease allele frequency $(q)$, the marker allele frequency $(r)$ will affect the power of this approach in individual pedigrees (fig 1 ).

Detailed enquiry into the family history of affected offspring of ostensible first cousin matings from ethnic groups in which consanguineous marriage is common usually shows the consanguinity to be much more complex than at first enquiry. In addition, ostensibly unrelated affected subjects from that population are often found to be related but in different sibships within the same pedigree. ${ }^{67}$ Efficient use of linkage information from such complex consanguineous families requires conventional linkage analysis. ${ }^{8}$

When pooling linkage information from different complex consanguineous families, the possibility of genetic heterogeneity must be considered. It is likely, however, that a limited number of genes will be responsible for a particular autosomal recessive disorder in an individual isolated population in which complex consanguinity is common. ${ }^{9}$

In populations in which consanguineous marriage is common, it has often been the usual pattern of marriage for a number of generations. It has been argued that long term inbreeding will reduce the power of this approach. ${ }^{10}$ Two factors will affect the usefulness of this approach in this situation. Prior or remote long term inbreeding $\left(\mathrm{F}^{\mathrm{p}}\right)$ combines with the 'bottleneck' of close inbreeding $\left(F^{c}\right)$ for a particular pedigree as $\mathrm{F}^{\mathrm{p}}+(1-\mathrm{F}) \mathrm{F}^{\mathrm{c}}$ which essentially reduces to $F^{p}+F^{c}$. The effect of substituting this in the above formula is to increase the apparent power of this approach. Another consequence of long term prior inbreeding is to 'redistribute' the disease and marker alleles with a reduction in the proportion of heterozygotes and increase the proportion of the two homozygotes in the population. ${ }^{11}$ The effect of this can be
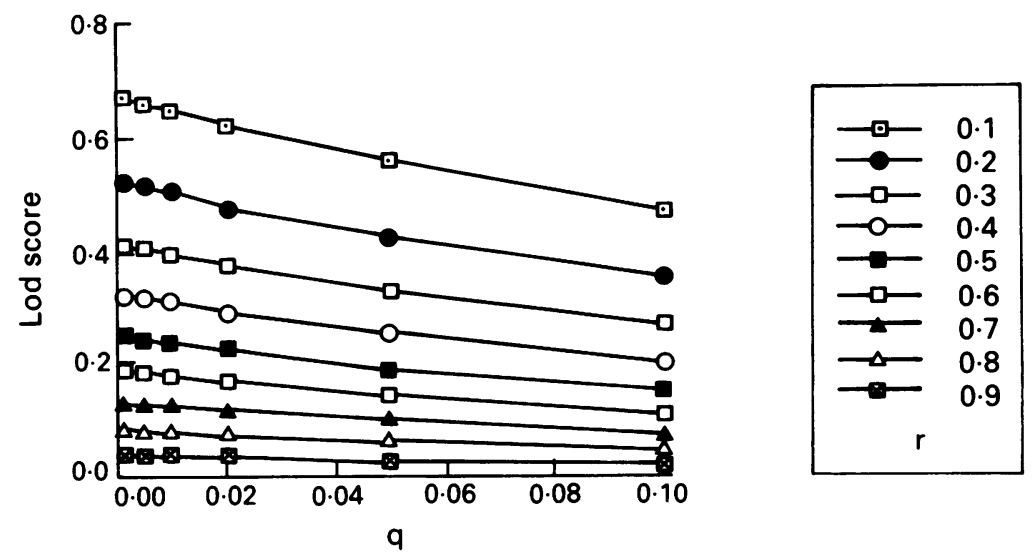

Figure 1 Effect on the lod score under complete linkage $(\theta=0)$ of the disease allele $(q)$ and marker allele $(r)$ for an affected offspring of first cousins.

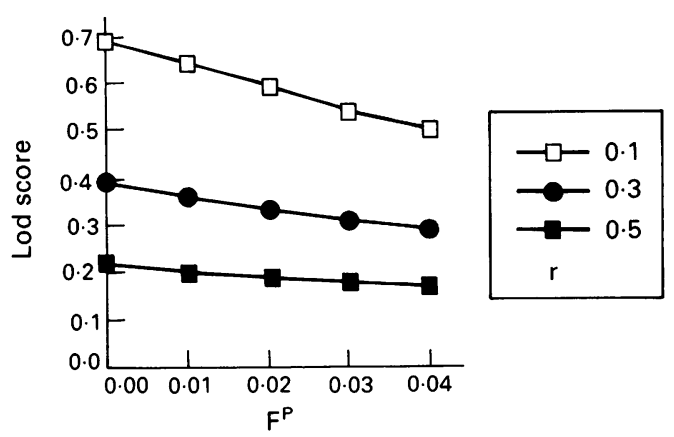

Figure 2 Effect of various prior inbreeding coefficient of the population $(F p)$ at $\theta=0$ on the lod score for a single affected offspring of first cousins for marker allele frequency $(r)$ and disease allele frequency $q=0.02$. 
corrected for by substituting $\mathrm{q}^{2}$ for $\mathrm{q}^{2}$ and $\mathrm{r}^{2 \prime}$ for $r^{2}$ similarly in the formula above where:

$\mathrm{q}^{2 \prime}=\mathrm{q}^{2}+\mathrm{F}^{\mathrm{p}} \mathrm{q}(1-\mathrm{q})$ and $\mathrm{r}^{2 \prime}=\mathrm{r}^{2}+\mathrm{F}^{\mathrm{p}} \mathrm{r}(1-\mathrm{r})$

and $\mathrm{F}^{\mathrm{p}}$ equals the coefficient of inbreeding of the population owing to prior inbreeding. The overall effect modelling for both of these effects reduces, to some extent, the power of this approach (fig 2).

Values for the long term background coefficient of inbreeding in populations in which complex consanguinity is common will need to be determined ${ }^{12}$ before using such families in linkage studies.

R F MUELLER Department of Clinical Genetics, Ashley Wing, St fames's Hospital, Beckett Street, Leeds LS9 7TF, UK

D T BISHOP

Imperial Cancer Research Fund Genetic Epidemiology Laboratory, Ashley Wing, St fames's Hospital,
Beckett Street, Leeds LS9 $7 T$, UK

1 Duyk G, Gastier JM, Mueller RF. Traces of her workings. Nature Genet 1992;2:5-8.

2 Wong FL, Cantor RM, Rotter JI. Sample-size considerations and strategies for linkage analysis in autosomal recessive disorders. $\mathrm{Am}$ f Hum Genet 1986;39:25-37.

3 Smith CAB. The detection of linkage in humans. F $R$ Stat Soc B 1953;15:153.

4 Lander ES, Botstein D. Homozygosity mapping: a way to map human recessive traits with the DNA of inbred children. Science 1987;236: 1567-70.

5 Morton NE. Genetic epidemiology of hearing impairment. Ann NY Acad Sci 1991;630:1631 .

6 Heney D, Mueller R, Turner G, et al. Familial microcephaly with normal intelligence in a matient with acute lymphoblastic leukaemia. patient with acute lym

7 Shaw NJ, Haigh D, Lealmann GT, Karbani G, Brocklebank JT, Dillon MJ. Autosomal recessive hypoparathyroidism with renal insufficiency and developmental delay. Arch Dis Child 1991;66:1191-4.

$8 \mathrm{Ott} \mathrm{J}$. Estimation of the recombination fraction in human pedigrees: efficient computation of the likelihood for human linkage studies. $A m \mathcal{F}$ Hum Genet 1974;26:773-5.

9 Morton N. Linkage and deafness. Hereditary Deafness Newsletter 1991;6:6.

10 Clarke A. Homozygosity mapping and Friedreich's ataxia. Lancet 1988;i:1168.

11 Morton N. Outline of genetic epidemiology. London: Karger, 1982

12 Darr A, Modell B. The frequency of consanguineous marriage among British Pakistanis. $\mathcal{f}$ Med Genet 1988;25:186-90.

\section{BOOK REVIEWS}

If you wish to order or require further information regarding the titles reviewed here, please write to or telephone the BMJ Bookshop, PO Box 295, London WC1H 9JR. Tel 071383 6244. Fax 0713836662 . Books are supplied post free in the UK and for BFPO addresses. Overseas customers should add $15 \%$ for postage and packing. Payment can be made by cheque in sterling drawn on a UK bank or by credit card (Mastercard, Visa, or American Express) stating card number, expiry date, and full name. (The price and availability are occasionally subject to revision by the Publishers.)

HLA 1991, Proceedings of the XI International Histocompatibility Workshop and Conference. Volumes 1 and 2 . Ed K Tsuji, M Aizawa, T Sasazuki. (Pp 1220; $£$ 175.00.) Oxford: Oxford Scientific Publications, Oxford University Press, 1992. ISBN $\begin{array}{llll}0 & 19 & 262217 & \mathrm{X}\end{array}$

These proceedings are the eleventh from the International Histocompatibility Workshop (IHW) community in a history of almost 30 years; they are dedicated to the memories of the late Hilliard Festenstein and Flemming Kissmeyer-Nielsen. Anyone wishing to keep abreast of developments in definition of the human Mhc, its alleles, and clinically relevant products will find these volumes essential reading and reference. This review of such a significant publication is best restricted to highlighting the contents as a 'taster' to anyone contemplating the cost of $£ 175$.

Volume 1 contains the 11th IHW report and data analyses with an overview and WHO Nomenclature Committee report listing the newly accepted alleles, specificities, and genes as part of HLA. This IHW may be the last to have a complete serological component and the antigen society reports are the key reference for laboratories using serology to define HLA-A,B,Cw,DR, and DQ specificities. Although monoclonal antibodies to HLA specificities have not replaced the use of alloantisera for routine typing they were used in IHW studies to define new specificities and could detect sequence polymorphisms and specific epitopes such as the definition of HLA-DR103, to which alloantisera do not exist. The use of HLA transfectants for generation of monoclonal antibodies resulted in studies of eight HLA class I and 13 HLA class II specific monoclonals.

The most valuable aspect of the 'DNA component' report is the wide range of techniques documented for anyone to try. The 11 th IHW protocols are inevitably already dated with the sequencing of many more HLA-DR and -DP alleles in the last 12 months.

A major objective of the IHW was the documentation of HLA alleles and specificities in different populations. This was achieved with some success and specific reports are included. The reference tables (155 pages) contain masses of data which are valuable to both researchers and routine histocompatibility testers.

Studies of HLA and disease associations now concentrate on defining specific susceptibility epitopes or seek functional relationships between specificities and infectious agents; the latter is best illustrated by HLA$\mathrm{B} 53$ positivity in malaria patients reviewed in volume 2 . Some 19 diseases were examined by serological and molecular techniques; these were those with established HLA associations (IDDM, RA, IMN, CD, etc) and new studies such as that of HIV. In the latter multicentre European study, $271 \mathrm{HIV}$ positive persons showed no significant HLA association and the report concludes "the analysis does not provide much evidence that susceptibility to become infected with HIV or to develop AIDS is controlled by the HLA system". Some of the disease studies are more comprehensive than others with the RA study being insubstantial.

Unfortunately the studies of HLA and organ transplantation were rather restricted in this IHW and suffered from world wide organisational difficulties. This is disappointing given that recent studies continue to emphasise the imperative for HLA matching in marrow transplantation and the advantages of outcome in HLA matched solid organ transplants. The HLA community must not forget that much of the drive to elucidate this gene complex came from the need to apply the knowledge gained to clinical transplantation.

The technique of immunoprecipitation of metabolically labelled HLA molecules followed by isoelectric focusing is established in the definition of specificities and is a good bridge between alleles and antigens of HLA class I (HLA-A,B,Cw). It formed a small but useful part of this IHW.

The interaction of HLA molecules with the $T$ cell receptor repertoire was studied with a number of approaches but one wonders if the HLA polymorphisms themselves really are the more functionally important partner? Notably, mixed lymphocyte culture assays and their associated complex data were not included in this IHW.

Other core IHW studies included C4, C2, and $\mathrm{Bf}$ complement genes which are encoded in the HLA-B/DR region, studies on human reproductive failure in $\mathbf{4 0 2}$ cases world wide of habitual aborter couples which showed no significant role for HLA genes, and studies of serum soluble HLA class I antigen.

Volume 2 of HLA 1991 has 122 pages of invited overviews and 531 pages of papers presented at the IHW Conference. The overviews are essential reading for state of the art information on HLA and are varied from HLA genetics, antigen presentation, gene regulation, disease associations and clinical applications to evolutionary mechanisms. These areas and others are expanded in the themes of contributed papers; the section on molecular typing methodology is particularly thought provoking.

Volume 2 contains 33 pages of IHW participants names and addresses; this is most useful but inclusion of fax numbers would have been a great help in contacting this world wide community.

At first glance the two volumes of $H L A$ 1991 appear forbidding. Do not be put off! They are easy to 'get around' and follow a logical structure. The larger of the books, volume 1 , contains the data needed for reference and will stay on the desk or in the laboratory while volume 2 can be carried home for digestion. The tradition of the IHWs is carried forward in these books and there are milestones such as population frequency data and methodology which will make them a continued reference. No HLA researcher or histocompatibility typer can be without them particularly since it is planned 